\title{
DNA Sequence
}

National Cancer Institute

\section{Source}

National Cancer Institute. DNA Sequence. NCI Thesaurus. Code C13299.

The sequence of nucleotide residues along a DNA chain. 